\title{
A PRODUÇÃO DO CONHECIMENTO SOBRE A EDUCAÇÃO FÍSICA NOS CURRÍCULOS DOS INSTITUTOS FEDERAIS DE EDUCAÇÃO, CIÊNCIA E TECNOLOGIA
}

\author{
T. N. MEDEIROS, C.B. BOSSLE, F. BOSSLE \\ Universidade Federal do Rio Grande do Sul \\ proftmedeiros@gmail.com
}

Artigo submetido em 06/03/2019 e aceito em 09/08/2019

DOI: $10.15628 /$ holos.2019.8367

\begin{abstract}
RESUMO
O presente estudo de cunho qualitativo objetivou compreender como a temática "Educação Física nos currículos dos Institutos Federais de Educação, Ciência e Tecnologia" vem sendo tratada na produção acadêmica científica. Realizamos um estudo de revisão de literatura no Catálogo de Dissertações e Teses da CAPES e no Portal de Periódicos da CAPES, utilizando os termos de busca: "Instituto Federal de Educação, Ciência e Tecnologia", "Educação Física" e "Currículo". Encontramos uma baixa produção sobre a temática tanto no Catálogo de Teses e Dissertações quanto no Portal de Periódicos da CAPES. Contudo, identificamos uma produção acadêmica qualificada da Revista Holos, sendo este periódico
\end{abstract}

científico o principal meio de socialização do conhecimento produzido nos Institutos Federais sobre a temática estudada. Por meio da revisão de literatura empreendida, foi possível compreender que os estudos encontrados são pautados por reflexões que demonstram haver um esforço significativo da Educação Física, área de conhecimento, de se localizar como componente curricular, no sentido de consolidar a proposta pedagógica dos Cursos Técnicos de Ensino Médio Integrado dos Institutos Federais, além de ressignificar o modo como os conteúdos são desenvolvidos e estabelecer sentido ao que se aprende e como se aprende.

PALAVRAS-CHAVE: Educação Física, Instituto Federal de Educação, Ciência e Tecnologia, Currículo.

\section{THE PRODUCTION OF KNOWLEDGE OF THE PHYSICAL EDUCATION IN THE CURRICULUM OF THE IFS}

\begin{abstract}
The current study qualitative has as purpose to understand how the subject "physical education in the curricula of the Federal Institutes of education, science and technology" has been treated in academic scientific production. We performed a literature review study in the Catalog of Dissertations and Theses of CAPES and Portal of Periodicals CAPES, using the search terms: "Federal Institute of education, science and technology", "physical education" and "Resume". We found a low production on the subject both in the catalog of theses and dissertations when journals Portal CAPES. However, we identified a qualified academic production of the
\end{abstract}

magazine Holos, scientific journal the main means of socialization of knowledge produced in Federal Institutions on the subject studied. Through the literature review undertaken it was possible to understand that studies are guided by reflections which demonstrate that there is a significant effort of physical education, knowledge area, to find how curricular component, in sense to consolidate the pedagogical proposal of technical courses in high school Integrated Federal Institutes, in addition to resign the way the contents are developed and establish direction to what you learn and how you learn.

KEYWORDS: Curriculum, Physical Education, The Federal Institute. 


\section{INTRODUÇÃO}

Os Institutos Federais de Educação, Ciência e Tecnologia (IFs) foram criados com a sanção da Lei no 11.892, de 29/01/2008 (BRASIL, 2008), que instituiu 38 IFs distribuídos pelo país. Os IFs atuam em todos os níveis e modalidades da educação profissional e tecnológica e foram estruturados a partir dos Centros Federais de Educação Tecnológica (CEFETS) e as Escolas Técnicas Federais, Agrotécnicas e Vinculadas às Universidades Federais. De acordo com Medeiros (2015), a proposta dos IFs é ministrar cursos técnicos de educação profissional em nível médio integrado e ofertar cursos técnicos subsequentes ao Ensino Médio, passando pela formação de jovens e adultos, por cursos superiores para aqueles que já concluíram o Ensino Médio, perpassando pela pesquisa e extensão, além da pós-graduação lato sensu e stricto sensu.

Os IFs possuem como premissa promover a educação técnica e de nível superior, ofertando à sociedade em geral o ensino público gratuito e de qualidade. Palma, Alves e Silva (2013, p. 84), destacam que o objetivo dos IFs é "suprir a demanda de mão de obra técnica qualificada, que tem aumentado no país, e agregar qualidade aos currículos, buscando integrar conhecimentos básicos e técnicos e preparar os estudantes para a vida e para o exercício da cidadania".

Segundo Pacheco (2011), os Institutos Federais têm o compromisso de intervir em suas respectivas regiões, identificando demandas e criando soluções técnicas e tecnológicas para o desenvolvimento sustentável com inclusão social para muito além da compreensão de uma educação profissional e tecnológica instrumentalizada. Para o autor, este processo em curso reafirma que a formação humana, cidadã, precede a qualificação para o labor, condicionado ao compromisso de assegurar aos profissionais formados a capacidade de manter-se em desenvolvimento. Ou seja, uma concepção de educação profissional e tecnológica, orientada para tríade de ações de ensino, pesquisa e extensão, pautada na integralidade entre ciência, tecnologia e cultura como dimensões indissociáveis da vida humana, articulada com a autonomia intelectual para o desenvolvimento da capacidade de investigação acadêmica científica.

Pacheco (2011) afirma ainda que esse novo projeto de Rede Federal de Ensino, com olhar para uma etapa da Educação Básica, torna os Institutos Federais de Educação, Ciência e Tecnologia o que há de mais significativo para o desenvolvimento da Educação em geral, mas, principalmente, para as políticas de educação profissional e tecnológica do Governo Federal. Para o autor, os IFs são caracterizados por uma política pública ousada e inovadora, sustentada em conceitos que antecipam as bases da escola contemporânea, comprometida com uma sociedade radicalmente democrática e socialmente justa.

O presente estudo decorre da iniciativa de um dos autores que se encontra imerso no trabalho de campo para elaboração de tese de doutoramento junto ao Programa de PósGraduação em Ciências do Movimento Humano (PPGCMH) da Universidade Federal do Rio Grande do Sul (UFRGS), que investiga a Educação Física (EFI) no currículo de um Instituto Federal de Educação, Ciência e Tecnologia (IF). A nossa intencionalidade por essa temática se dá por entendermos que o projeto institucional dos IFs se constitui como uma nova perspectiva progressista de ensino para a Educação brasileira. 
Deste modo, emerge a necessidade de compreender a produção acadêmica existente sobre essa temática a partir de uma revisão de literatura. Neste sentido, o presente estudo propõe compreender como a temática "Educação Física nos currículos dos Institutos Federais de Educação, Ciência e Tecnologia" vem sendo tratada na produção acadêmica científica.

\section{REFERENCIAL TEÓRICO}

Compreendemos o significado de "currículo", sustentado na fundamentação teórica de Sacristán (2013) que estabelece relação com a realidade e os sistemas educacionais, na qual oferece condições de inclusão, ao mesmo tempo que serve como instrumento de diálogo, debate e discussão da sociedade, cultura e economia, sem que este sirva como mero ordenador de conteúdos. O currículo desempenha diferentes funções, considerando as características específicas em diversos níveis de ensino. Para o autor, essa condição dificulta a clareza da compreensão sobre a teoria do currículo, pois entrecruzam os discursos próprios do sistema escolar com as tradições práticas e teóricas de ensino. Sacristán (2000) aponta ainda que:

O currículo, em seu conteúdo e nas formas através das quais se nos apresenta e se apresenta aos professores e aos alunos, é uma opção historicamente configurada, que se sedimentou dentro de uma determinada trama cultural, política, social e escolar; está carregado, portanto, de valores e pressupostos que é preciso decifrar. Tarefa a cumprir tanto a partir de um nível de análise políticosocial quanto a partir do ponto de vista de sua instrumentação "mais técnica", descobrindo os mecanismos que operam em seu desenvolvimento dentro dos campos escolares (SACRISTÁN, 2000, p. 17).

Portanto, o currículo está subscrito em um campo de disputas, seus valores e pressupostos são isentos de neutralidade. Sacristán (2000) destaca que a assepsia científica também não deve estar presente no mundo educativo, pois o projeto cultural e o modo de socialização que a escola promove para os seus alunos não é neutro. Neste sentido, Apple (2001) reforça a ideia de que a educação está diretamente implicada na política cultural, portanto nunca é neutra e sempre parte da tradição seletiva feita por alguém a partir da visão de um grupo que entende o seu conhecimento como legítimo. Apple (2001, p. 53) aponta ainda que o currículo "é produzido pelos conflitos, tensões e compromissos culturais, políticos e econômicos que organizam e desorganizam um povo".

Neira e Nunes (2009), afirmam que o fato de ensinar determinados códigos no currículo e validar seus conteúdos, faz com que a escola assimile lentamente a sua função socializadora da educação. Porém, os autores sugerem uma reflexão sobre os valores, atitudes e conhecimentos que estão implicados a esse currículo que representa disputa de poder, "pois quem participa da decisão sobre a escolha dos conteúdos detém o poder sobre o processo de ensino" (NEIRA; NUNES, 2009, p. 59). Essa disputa de poder também acontece na Educação Física escolar, pois o currículo está marcado por diferentes concepções de ensino e diversas possibilidades de conhecimento. Para os autores, os modelos de currículo ginástico, esportivo, globalizante, desenvolvimentista ou saudável, praticados no ensino da EFI, confrontam os princípios de participação solidária, reconstrução cultural, transformação social e afirmação da democracia (NEIRA; NUNES, 2009). 
O currículo da Educação Física é reconhecido como um projeto cultural que proporciona aos alunos a aprendizagem de conteúdos determinados e organizados por condições políticas, ou seja, o currículo reflete o resultado de um processo particular de interesses das classes e dos grupos dominantes (NEIRA \& NUNES, 2009). Concordamos com os autores ao se posicionarem de modo contra hegemônico reconhecendo os fortes apelos culturais, exercidos pelo bloco hegemônico nos meios midiáticos, o modelo de produção de conhecimento acadêmico e o modismo como forma de dominação social e cultural. Neste sentido, compartilhamos do pensamento de Pirolo et al (2014) entendendo que um currículo fundamentado na perspectiva crítica busca uma noção ampliada de práticas e saberes escolares, orientados para a construção de uma prática pedagógica, sustentada na cultura e nos interesses das classes populares, promovendo uma transformação sobre o olhar da cidadania popular e das organizações sociais na defesa de equidade dos direitos e oportunidades daqueles que mais necessitam.

\section{METODOLOGIA}

O presente estudo está pautado em uma revisão de literatura de cunho qualitativo. Segundo Cresweel (2014), a pesquisa qualitativa parte do pressuposto de estruturas interpretativas e/ou teóricas, articuladas com os significados atribuídos a um problema social e humano. Neste caso, o presente estudo promove ênfase ao processo de pesquisa, sustentado nos pressupostos filosóficos para o olhar interpretativo, bem como nos procedimentos de coleta, análise e interpretação das informações tanto indutiva quanto dedutiva que promovem a reflexão do pesquisador e a contribuição para a literatura acadêmica e científica.

Para Noronha e Ferreira (2000), os estudos de revisão

analisam a produção bibliográfica em determinada área temática, dentro de um recorte de tempo, fornecendo uma visão geral ou um relatório do estado-da-arte sobre um tópico específico, evidenciando novas ideias, métodos, subtemas que têm recebido maior ou menor ênfase na literatura selecionada. (NORONHA \& FERREIRA, 2000, p. 191)

Para dar conta da revisão de literatura proposta, realizamos uma busca no Catálogo de Teses e Dissertações da CAPES e no Portal de Periódicos da CAPES usando os seguintes termos: "Instituto Federal de Educação, Ciência e Tecnologia", "Educação Física" e "Currículo". Destacamos que, para busca em ambos os bancos de dados, fez-se pertinente a análise dos documentos datados a partir de 29 de janeiro de 2008, ou seja, data da criação da Lei no 11.892 que institui 38 Institutos Federais no país (BRASIL, 2008). Para a análise do material levantado, utilizamos a metodologia da Análise de Conteúdo de Bardin (2011).

\section{RESULTADOS E DISCUSSÃO}

Iniciamos o levantamento da produção acadêmica disponível sobre a temática pesquisada no Catálogo de Teses e Dissertações da CAPES em janeiro de 2018. A revisão de literatura, 
empreendida na referida base de dados, respeitou cinco etapas. Na primeira, utilizamos em conjunto os termos: "Instituto Federal de Educação, Ciência e Tecnologia", "Educação Física" e "Currículo" no campo de busca geral e encontramos 1.098 .033 resultados. Na segunda etapa passamos a realizar o refinamento desse resultado. Marcamos, inicialmente, o "campo" do Tipo Mestrado e Doutorado. Em seguida, acrescentamos a marcação do "campo" do Tipo Ano: 2018, 2017, 2016, 2015, 2014, 2013 e 2012, 2011, 2010, 2009, 2008. Encontramos 623.000 resultados. A seguir, refinamos a busca marcando o "campo" Área Conhecimento: Educação Física (2293) e Educação Física (3876) ${ }^{1}$ e, por fim, assinalamos o "campo" Área Avaliação: Educação Física (2293) e Educação Física (3876). Como resultado deste refinamento, encontramos 6.169 títulos.

$\mathrm{Na}$ terceira etapa realizamos a leitura dos títulos das dissertações e teses, tendo como objetivo avaliar se nestes continham os termos usados para a busca e/ou estavam relacionados à temática do presente estudo. Selecionamos nove estudos a partir deste critério. Na quarta etapa, organizamos o Quadro 1 com os resultados da busca. O quadro foi estruturado em cinco colunas: na primeira, destacamos o título do estudo selecionado, na segunda apresentamos o tipo de estudo encontrado (tese ou dissertação), na terceira coluna apontamos a Instituição de Ensino Superior (IES) na qual foi produzido o estudo, na quarta coluna indicamos a autoria e o ano do estudo, na quinta incluímos o endereço eletrônico e na sexta assinalamos a data na qual acessamos o estudo pela primeira vez.

A partir da organização do Quadro 1 passamos para a quinta etapa, que consistiu em analisar individualmente as Teses e Dissertações e a sua relevância para a presente investigação, realizando, inicialmente, a leitura do resumo das pesquisas e, posteriormente, os estudos em sua íntegra. É necessário destacar que as pesquisas nas quais os autores não disponibilizaram o arquivo contendo o texto completo não foram considerados para análise.

Quadro 1: Revisão Literatura no Catálogo de Teses e Dissertações da CAPES

\begin{tabular}{|c|c|c|c|c|c|}
\hline TÍTULO & $\begin{array}{l}\text { TIPO DE } \\
\text { ESTUDO }\end{array}$ & IES & REFERÊNCIA & $\begin{array}{c}\text { ENDEREÇO } \\
\text { ELETRÔNICO }\end{array}$ & $\begin{array}{l}\text { DATA DE } \\
\text { ACESSO }\end{array}$ \\
\hline $\begin{array}{l}\text { A oferta do esporte para o } \\
\text { aluno com deficiência no } \\
\text { Instituto Federal do Paraná } \\
\text { - IFPR, campus Paranaguá: } \\
\text { um movimento de } \\
\text { reprodução ou resistência? }\end{array}$ & $\begin{array}{l}\text { Dissertação } \\
\text { de } \\
\text { Mestrado }\end{array}$ & UFPR & $\begin{array}{c}\text { Cancella } \\
(2018)\end{array}$ & $\begin{array}{l}\frac{\text { https://sucupira.c }}{\text { apes.gov.br/sucu }} \\
\text { pira/public/consu } \\
\frac{\text { Itas/coleta/trabal }}{\text { hoConclusao/vie }} \\
\frac{\text { wTrabalhoConclu }}{\text { sao.jsf?popup=tru }} \\
\frac{\text { e\&id trabalho=60 }}{\underline{31316}}\end{array}$ & $07 / 12 / 2018$ \\
\hline $\begin{array}{l}\text { Práticas curriculares na } \\
\text { educação física: análise dos } \\
\text { jogos escolares do Instituto } \\
\text { Federal Sertão } \\
\text { Pernambucano }\end{array}$ & $\begin{array}{c}\text { Dissertação } \\
\text { de } \\
\text { Mestrado }\end{array}$ & $\begin{array}{c}\text { UNIVAS } \\
\mathrm{F}\end{array}$ & $\begin{array}{c}\text { Lima } \\
(2017)\end{array}$ & $\begin{array}{l}\frac{\text { https://sucupira.c }}{\text { apes.gov.br/sucu }} \\
\text { pira/public/consu } \\
\frac{\text { ttas/coleta/trabal }}{\text { hoConclusao/vie }} \\
\text { wTrabalhoConclu }\end{array}$ & $07 / 12 / 2018$ \\
\hline
\end{tabular}

\footnotetext{
${ }^{1}$ A própria plataforma apresenta a repetição da opção Educação Física no "campo" Área de Conhecimento, portanto assinalamos os dois "campos" onde apareciam esse termo. O mesmo aconteceu no "campo" Área Avaliação.
} 


\begin{tabular}{|c|c|c|c|c|c|}
\hline & & & & $\begin{array}{l}\frac{\text { sao.jsf?popup }=\operatorname{tru}}{\text { e\&id trabalho }=57} \\
\underline{01430}\end{array}$ & \\
\hline $\begin{array}{l}\text { A ausência da educação } \\
\text { física no currículo da } \\
\text { Educação de Jovens e } \\
\text { Adultos: um estudo no } \\
\text { Campus Rio de Janeiro do } \\
\text { Instituto Federal de } \\
\text { Educação, Ciência } \\
\begin{array}{l}\text { Tecnologia do Rio de } \\
\text { Janeiro (IFRJ) }\end{array}\end{array}$ & $\begin{array}{l}\text { Dissertação } \\
\text { de } \\
\text { Mestrado }\end{array}$ & $\begin{array}{l}\text { Universi } \\
\text { dade } \\
\text { Salgado } \\
\quad \text { de } \\
\text { Oliveira }\end{array}$ & $\begin{array}{c}\text { Carvalho } \\
\text { (2017) }\end{array}$ & $\begin{array}{l}\frac{\text { https://sucupira.c }}{\text { apes.gov.br/sucu }} \\
\frac{\text { pira/public/consu }}{\text { Itas/coleta/trabal }} \\
\frac{\text { hoConclusao/vie }}{\text { wTrabalhoConclu }} \\
\frac{\frac{\text { sao.jsf?popup=tru }}{\text { e\&id trabalho }=57}}{\text { 82549 }}\end{array}$ & $07 / 12 / 2018$ \\
\hline $\begin{array}{l}\text { Narrativas de Experiências } \\
\text { Profissionais de Docentes } \\
\text { de Educação Física no } \\
\text { Ensino Técnico Integrado } \\
\text { do Instituto Federal de } \\
\text { Educação, Ciência e } \\
\text { Tecnologia }\end{array}$ & $\begin{array}{l}\text { Dissertação } \\
\text { de } \\
\text { Mestrado }\end{array}$ & UFES & $\begin{array}{l}\text { Mendonça } \\
\text { (2016) }\end{array}$ & $\begin{array}{l}\frac{\text { http://repositorio }}{\text { ufes.br/bitstrea }} \\
\frac{\mathrm{m} / 10 / 7313 / 1 / \text { tes }}{\text { e } 9839 \text { TESE Gil }} \\
\frac{\text { berto\%20Cabral.p }}{\underline{\text { df }}}\end{array}$ & $07 / 12 / 2018$ \\
\hline $\begin{array}{l}\text { Esporte, Lazer e Cultura: os } \\
\text { significados dos projetos de } \\
\text { esporte e lazer do Instituto } \\
\text { Federal do Norte de Minas } \\
\text { Gerais - Campus Januária } \\
\text { para alunos participantes e } \\
\text { não participantes }\end{array}$ & $\begin{array}{l}\text { Dissertação } \\
\text { de } \\
\text { Mestrado }\end{array}$ & UNIMEP & $\begin{array}{l}\text { Santos } \\
\text { (2016) }\end{array}$ & $\begin{array}{l}\frac{\text { https://www.uni }}{\text { mep.br/phpg/bib }} \\
\frac{\text { dig/aluno/visualiz }}{\text { a.php?cod=1535 }}\end{array}$ & $07 / 12 / 2018$ \\
\hline $\begin{array}{l}\text { Esporte de Aventura na } \\
\text { Escola: possibilidades de } \\
\text { diálogo com a mídia- } \\
\text { educação }\end{array}$ & $\begin{array}{l}\text { Dissertação } \\
\text { de } \\
\text { Mestrado }\end{array}$ & UFRN & Sousa (2016) & $\frac{\frac{\text { https://repositori }}{\text { o.ufrn.br/jspui/ha }}}{\frac{\text { ndle/123456789/ }}{\underline{21343}}}$ & $07 / 12 / 2018$ \\
\hline $\begin{array}{l}\text { Participação de Alunos do } \\
\text { Ensino Médio Integrado ao } \\
\text { Ensino Profissionalizante } \\
\text { em Atividades } \\
\text { Extracurriculares } \quad \text { de } \\
\text { Esporte e Lazer em um } \\
\text { Campus de um Instituto } \\
\text { Federal em Minas Gerais- } \\
\text { MG }\end{array}$ & $\begin{array}{l}\text { Dissertação } \\
\text { de } \\
\text { Mestrado }\end{array}$ & UNIMEP & $\begin{array}{l}\text { Ramos } \\
(2015)\end{array}$ & $\begin{array}{l}\frac{\text { http://www.unim }}{\text { ep.br/phpg/bibdi }} \\
\frac{\text { g/aluno/visualiza. }}{\text { php?cod=1486 }}\end{array}$ & $07 / 12 / 2018$ \\
\hline $\begin{array}{l}\text { A Educação Física no } \\
\text { Currículo de Escolas } \\
\text { Profissionalizantes da Rede } \\
\text { Federal: uma disciplina em } \\
\text { processo de "mutação" }\end{array}$ & $\begin{array}{c}\text { Tese de } \\
\text { Doutorado }\end{array}$ & UFRGS & Silva (2014) & $\frac{\frac{\text { https://lume.ufrg }}{\text { s.br/handle/1018 }}}{\underline{3 / 99037=1}}$ & $07 / 12 / 2018$ \\
\hline $\begin{array}{l}\text { Intervenção em Educação } \\
\text { Física escolar: promovendo } \\
\text { atividade física e saúde no } \\
\text { Ensino Médio }\end{array}$ & $\begin{array}{l}\text { Dissertação } \\
\text { de } \\
\text { Mestrado }\end{array}$ & UFPel & Otte (2013) & $\begin{array}{l}\frac{\text { https://wp.ufpel. }}{\text { edu.br/ppgef/file }} \\
\frac{\text { s/2014/04/Jorge- }}{\text { Otte.pdf }}\end{array}$ & $07 / 12 / 2018$ \\
\hline
\end{tabular}

Fonte: Os próprios autores. 
Apresentamos nesta análise nove estudos, sendo uma Tese de Doutorado (SILVA, 2014) e oito Dissertações de Mestrado (CANCELLA, 2018, LIMA, 2017, CARVALHO, 2017, MENDONÇA, 2016, SANTOS, 2016, SOUSA, 2016, RAMOS, 2015, OTTE, 2013), sendo que, deste total, três foram realizadas em Instituições de Ensino Superior (IES) privadas e seis em IES públicas. Todas as pesquisas se referem ao tema "Educação Física" de modo central, assim como ao "Instituto Federal de Educação, Ciência e Tecnologia". Foi possível verificar que os estudos abordam o tema currículo, porém somente três deles enfatizam esta temática de forma central.

Depois deste primeiro momento de revisão de literatura, passamos ao levantamento realizado no Portal de Periódicos da CAPES. Destacamos que os procedimentos de busca respeitaram as etapas anteriormente citadas. Os termos "Instituto Federal de Educação, Ciência e Tecnologia”, Educação Física" e "Currículo" também foram usados em conjunto.

O levantamento no Portal de Periódicos da CAPES resultou na obtenção de 57 títulos usando os termos acima descritos no campo "buscar assunto". Partindo deste resultado, realizamos a leitura de todos os títulos e resumos para dar evidência aos trabalhos que utilizaram os termos escolhidos como centrais nos estudos. Dos 57 títulos, restaram somente três em acordo com este critério. Em seguida, passamos para a leitura minuciosa dos artigos selecionados e para a análise propriamente dita. Destacamos que todos os artigos analisados estão disponíveis online.

Apresentamos, a seguir, o Quadro 2, composto pelos artigos encontrados e organizados em cinco colunas. Na primeira coluna consta o título do artigo, na segunda o nome do periódico científico no qual foi publicado, na terceira coluna aparece a referência bibliográfica, na quarta há o DOI (Digital Object Identifier) e na quinta a sinalização da data na qual os artigos foram acessados.

Quadro 2: Revisão de literatura no Portal de Periódicos da CAPES.

\begin{tabular}{|c|c|c|c|c|}
\hline TíTULO & $\begin{array}{l}\text { PERIÓ } \\
\text { DICO }\end{array}$ & REFERÊNCIA & DOI & $\begin{array}{l}\text { DATA DE } \\
\text { ACESSO }\end{array}$ \\
\hline $\begin{array}{c}\text { Possibilidades e Desafios da Educação } \\
\text { Física como Componente Curricular no } \\
\text { Processo de Expansão Regional do } \\
\text { Instituto Federal de Educação, Ciência } \\
\text { e Tecnologia do Rio Grande do Norte - } \\
\text { IFRN }\end{array}$ & Holos & Batista et al (2014) & $\begin{array}{c}\text { 10.15628/hol } \\
\text { os.2014.201 } \\
8\end{array}$ & $12 / 12 / 2018$ \\
\hline $\begin{array}{l}\text { Corpo, Aprendizagem e Cultura de } \\
\text { Movimento: uma experiência } \\
\text { pedagógica com o ensino do conteúdo } \\
\text { jogo nas aulas de Educação Física do } \\
\text { IFRN }\end{array}$ & Holos & $\begin{array}{l}\text { Batista, Oliveira e } \\
\text { Melo (2012) }\end{array}$ & $\begin{array}{c}10.15628 / \mathrm{hol} \\
\text { os.2012.106 } \\
0\end{array}$ & $12 / 12 / 2018$ \\
\hline $\begin{array}{c}\text { A Educação Física no PROEJA do IFRN } \\
\text { - Campus Natal Zona Norte: uma } \\
\text { experiência pedagógica }\end{array}$ & Holos & $\begin{array}{l}\text { Souza Filho e Souza } \\
\text { (2010) }\end{array}$ & $\begin{array}{c}10.15628 / \mathrm{hol} \\
\text { os.2010.366 }\end{array}$ & $12 / 12 / 2018$ \\
\hline
\end{tabular}

Fonte: Os próprios autores

Nesta etapa do estudo, ao analisar os três artigos selecionados (BATISTA et al., 2014, BATISTA; OLIVEIRA; MELO, 2012, SOUZA FILHO; SOUZA, 2010), verificamos que todos foram 
realizados no Instituto Federal do Rio Grande do Norte. Todas as pesquisas se referem ao tema "Educação Física" de modo central, assim, como ao "Instituto Federal de Educação, Ciência e Tecnologia". Porém, no que se refere ao "currículo" somente um artigo aborda o tema de modo central.

Depois de realizar os levantamentos, passamos para a análise propriamente dita. Visando proporcionar profundidade na análise e no diálogo com as referências bibliográficas, organizamos os estudos encontrados em três categorias nomeadas da seguinte forma: Esportivização, Formação Docente, Etapas de Ensino.

\section{Esportivização}

Essa categoria de análise contempla os estudos que abordaram discussões sobre a esportivização da Educação Física escolar de modo central ou periférico. Para González (2008, p. 170), esportivização seria o "ato ou efeito de converter ou transformar uma prática corporal em esporte ou uma prática social em assumir os códigos próprios desse fenômeno". Ilha e Hypolito (2016, p. 176) destacam que os esportes são "conteúdos previstos no currículo do componente e não se nega sua importância, porém, algumas modalidades têm ocupado espaço demasiado diante da gama dos saberes da Educação Física possíveis de serem trabalhados na escola, bem como os modos de tratá-los". Os autores denominam esportivização justamente essas dimensões privilegiadas nas práticas curriculares da Educação Física escolar.

A presente categoria de análise compõe os estudos de Cancella (2018), Santos (2016), Ramos (2015), Silva (2014) e Batista et al (2014). Cancella (2018) investigou como se constitui a oferta do esporte para a pessoa com deficiência no Instituto Federal do Paraná (IFPR), campus Paranaguá e objetivou identificar se há um movimento de reprodução ou resistência quanto à oferta do esporte que valoriza os princípios do rendimento para os alunos com deficiência. $O$ estudo, produzido na Universidade Federal do Paraná, configura-se como uma pesquisa qualitativa, de cunho descritivo e analítico, com as informações orientadas a partir de uma revisão histórica da legislação esportiva no Brasil, e da análise do endereço eletrônico da Rede Federal Educação Profissional, Científica e Tecnológica (EPCT), do Plano de Desenvolvimento Institucional (PDI) do IFPR (2014-2018), do Projeto Político Pedagógico (PPP) do campus Paranaguá e dos Planos de Ensino Curriculares da Educação Física (PECEFs). Cancella (2018) estabeleceu uma contextualização do conteúdo analisado em três capítulos: teórico, legislativo e documental.

A partir das informações recolhidas, o autor afirma que a ideia de "Habitus", sustentado por Pierre Bourdieu se encontra representado a partir do senso de jogo, do que se deve fazer em determinada situação no sentido de antecipar o futuro em que as práticas produzem determinadas condições que levam a própria reprodução do produto reconhecido no modelo social vigente. Também foram identificados os agentes e as instituições que compõem o subcampo do esporte escolar, bem como a imposição de uma cultura dominante que valoriza os princípios do rendimento esportivo. Cancella (2018) verificou, ainda, a ausência de ações voltadas para a prática esportiva na perspectiva do aluno com deficiência e a reprodução da cultura esportiva dominante.

Cancella (2018), identifica que pensar as políticas de ensino dos IFs sustentado na perspectiva do esporte significa limitar a compreensão desse fenômeno cultural e sua implicação 
social. No entanto, o autor destaca que encontrou, nos PECEFs do campus Paranaguá, ações diferenciadas e voltadas para a prática de vivências inclusivas no esporte, que pode se constituir em um movimento de resistência à cultura esportiva dominante.

A Dissertação de Mestrado de Ramos (2015), produzida na Universidade Metodista de Piracicaba, busca verificar, por meio de um estudo de caso, a participação dos alunos dos cursos profissionalizantes integrados ao Ensino Médio nas atividades do Programa de Esporte e Lazer desenvolvidas em um Campus de um Instituto Federal localizado no estado de Minas Gerais, assinalando possíveis caminhos para a otimização do referido programa. Além disto, o autor buscou traçar o perfil dos alunos, verificando sua frequência e participação ou não do programa, as possíveis causas para a não participação, a distribuição das atividades curriculares e extracurriculares, e o entendimento dos gestores a respeito do programa. 0 estudo de caso contou com a participação de 370 alunos que responderam a um questionário, além de entrevistas semiestruturadas com os gestores da instituição e análise de documentos.

Ramos (2015) aponta que a maioria dos alunos participantes da pesquisa são do gênero masculino, possuem faixa etária entre 15 e 17 anos, utilizam o ônibus como meio de transporte, não trabalham, não apresentam problemas de saúde e percebem renda familiar entre um e cinco salários mínimos. Os alunos que residem na instituição, em regime de semi-internato, são os que mais participam do programa. A falta de tempo e de interesse, o acúmulo de tarefas curriculares, a distribuição do esporte e do lazer no quadro de atividades da instituição, os constrangimentos experienciados e a falta de informação foram as causas mais citadas para não participação no programa.

Quanto aos gestores, Ramos (2015, p. 52) constatou que o entendimento sobre o programa de atividades extracurriculares de esporte e lazer passa por uma "visão funcionalista do programa", entendendo o mesmo como "controle do tempo livre dos jovens" para a "manutenção da ordem". Ramos (2015, p. 52) aponta ainda que alguns gestores "ressaltam a importância da prática de esportes e lazer de uma forma genérica e apoiados no senso comum". Dificuldades em relação à infraestrutura da Instituição e à conscientização da comunidade, a deficiência das estruturas para a realização das atividades e as barreiras financeiras também foram citadas como complicadoras para o desenvolvimento do programa. Além disto, gestores também destacam a esportivização excessiva nas aulas de Educação Física escolar como motivo da não participação dos alunos no programa, pois "privilegia a competição e não trabalha outras possibilidades do esporte, como o esporte de participação" (RAMOS, 2015, p. 53).

A Dissertação de Mestrado de Santos (2016), também produzida na Universidade Metodista de Piracicaba, apresenta uma temática próxima ao estudo empreendido por Ramos (2015). Santos (2016) objetivou analisar o esporte e o lazer a partir de um referencial sociocultural, bem como, identificar e analisar os significados dos projetos de esporte e de lazer do Instituto Federal do Norte de Minas Gerais - Campus Januária, para alunos participantes e não participantes de tais projetos. A investigação caracterizou-se por pesquisa bibliográfica e de campo, utilizou como instrumentos a entrevista semiestruturada, o questionário e a observação participante e foi realizada com 40 alunos, incluindo participantes e não participantes dos projetos de esporte e lazer da Instituição. 
Santos (2016) destaca que no Campus Januário existem projetos de esporte e lazer que oferecem aos alunos diversas práticas corporais após o horário escolar, além disso, os estudantes também são estimulados a participar de competições esportivas. O autor aponta que, aparentemente, não há uma seleção prévia de alunos para a participação nos projetos, mas a ideia principal é a preparação para as competições. Para escolher os alunos que vão participar dessas competições é necessária a realização de uma seleção, pois o número de participantes nestes eventos é restrito.

Um fato que provoca a não participação dos alunos nos projetos diz respeito à perda de aulas durante as competições e os treinos, prejudicando a vida escolar. Já os alunos participantes dos projetos associam os treinos esportivos à diversão, à possibilidade de viajar para as competições e não acreditam que essas atividades atrapalham o rendimento escolar. De modo geral, os alunos entendem que "os projetos contemplam o descanso, o divertimento e o desenvolvimento pessoal e social" (SANTOS, 2016, p. 171). Porém, os alunos menos habilidosos demonstram insegurança para fazer parte dos projetos, pois poderiam estar sujeitos a constrangimentos (SANTOS, 2016).

Quanto à insegurança evidenciada pelos alunos menos habilidosos, Ilha e Hypólito (2016) comentam que

os princípios do esporte de rendimento que atravessam as práticas curriculares da Educação Física são visibilizados, principalmente, pela prática dos jogos que são competitivos e que excluem os menos habilidosos, seja por interferência de colegas, do professor ou do próprio aluno que não se sente bem de não ter uma boa performance esportiva perante os demais (ILHA; HYPÓLITO, 2016, p. 177).

As práticas docentes parecem desempenhar um papel importante na perpetuação ou rompimento com este modelo esportivizante e excludente. Neste sentido, o artigo de Batista et al (2014) trata das reflexões teóricas, originadas durante os estudos de pós-graduação, desenvolvidos pelos autores, articulando suas práticas docentes com as ações pedagógicas do componente curricular Educação Física e o conjunto de conhecimentos relativo aos conteúdos temáticos da mesma no IFRN durante o período de cinco anos. Os autores buscaram discutir a relevância sociocultural do IFRN, assim como a função social da Educação Física como componente curricular no processo de formação do Ensino Médio Integrado.

Ao se referirem à função social da Educação Física no período de formação do Ensino Médio Integrado do IFRN, Batista et al (2014) estão sustentados na Lei 9.394/96 (BRASIL, 1996), que estabelece as Diretrizes e Bases para a Educação Nacional. Nesse documento, o item que trata do Ensino Médio, seção IV, artigo 35, evidencia o compromisso social da educação, no sentido de que o ensino deve proporcionar conhecimentos para o trabalho e a cidadania do educando com formação ética e desenvolvimento da autonomia intelectual e pensamento crítico. Os autores destacam que o coletivo docente do IFRN desenvolveu uma proposta pedagógica de ensino da Educação Física que pode contribuir para a produção significativa de conhecimento. Essa proposta está amparada nas concepções pedagógicas da Abordagem Crítico-Emancipatória (KUNZ, 1991), 
Abordagem Crítico-Superadora (SOARES et al., 2012) e Aulas abertas à experiência (HILDEBRANDT, 1986).

Batista et al. (2014) apontam que ainda existe a necessidade de consolidação da prática pedagógica da Educação Física. Os autores são enfáticos ao abordar a centralidade do docente como elemento principal da efetivação da proposta pedagógica específica da Educação Física escolar, a fim de romper com as perspectivas tradicionais do ensino da Educação Física que representam o modelo esportivista, mecanicista e tecnicista que, segundo os autores, ainda perdura nos Institutos Federais.

Esta discussão sobre a esportivização da Educação Física também aparece na Tese de Silva (2014), porém de forma central. O estudo é vinculado à Universidade Federal do Rio Grande do Sul e apresenta como estratégia de pesquisa o estudo de caso. Silva (2014) buscou compreender o processo adaptativo da Educação Física ao currículo de quatro Campi do Instituto Federal de Educação, Ciência e Tecnologia do Rio Grande do Sul (IFRS): Bento Gonçalves, Porto Alegre, Rio Grande e Sertão. O autor realizou uma releitura histórica da Educação Física, bem como, da Educação Física nos cursos profissionalizantes, a partir da política educacional para a Educação Profissional, dos marcos regulatórios, formação propedêutica versus formação profissionalizante. Silva (2014) identificou que o modelo esportivista das escolas propedêuticas passa facilmente a se adaptar ao currículo do ensino profissionalizante, desde as décadas de 1960 e 1970.

O modelo esportivista identificado por Silva (2014) está fundamentado no estudo de Darido e Rangel (2011), os quais afirmam que esse modelo busca a melhora do rendimento esportivo a partir da eficiência, produtividade e perseverança para o desempenho esportivo de excelência. Esse modelo também pode ser reconhecido como mecanicista, tradicional e tecnicista no meio acadêmico e passou a ser duramente criticado a partir dos anos 1980 por não representar a Educação Física como área de conhecimento. Para Silva (2014), o currículo do ensino dos Institutos Federais sofreu alterações significativas a partir da Lei no 11.892 (BRASIL, 2008), desenvolvendo uma proposta educacional que contemplasse os cursos técnicos integrados ao Ensino Médio profissionalizante.

Silva (2014) identifica que pequenas mudanças estão acontecendo na Educação Física esportivista nos currículos dos Campi do IFRS e entende que este deve ser o início de um significativo processo de mudança para a Educação Física nas Escolas Profissionalizantes. Nos Campi Bento Gonçalves, Rio Grande e Sertão parece estar havendo uma tentativa de romper com o modelo esportivista a partir de uma "aproximação da Educação Física com conhecimentos anatômicos e fisiológicos do corpo humano e/ou voltados à preocupação com a saúde do trabalhador em seu ambiente de trabalho (Primeiros Socorros, Ergonomia e Educação Postural)" (SILVA, 2014, p. 133). Já o Campus Porto Alegre apresenta ruptura com o modelo esportivista, apresentando aproximação da Educação Física aos cuidados com a saúde do trabalhador (Ergonomia e Educação Postural).

\section{Formação Docente}


Essa categoria de análise abarca os estudos que enfatizam a formação docente, suas experiências profissionais e histórias de vida. Essas temáticas foram agrupadas, pois Molina Neto, Bossle e Wittizorecki (210, p. 133) apontam que a "formação docente se faz articulada ao trabalho docente". As Dissertações de Mestrado de Lima (2017) e Mendonça (2016) compõem a presente categoria.

A Dissertação de Mestrado de Lima (2017), produzida na Universidade Federal do Vale do São Francisco (UNIVASF), aborda os jogos escolares do Instituto Federal Sertão Pernambucano na sua relação com o currículo, esporte e educação física escolar. O estudo também apresenta discussões no campo das teorias de currículo, além de oferecer um debate sobre o esporte enquanto produção cultural e acerca dos jogos escolares enquanto prática curricular. $O$ objetivo geral do estudo foi compreender a dinâmica dos jogos escolares do IF Sertão Pernambuco enquanto prática curricular e, para tal, foram utilizados dois instrumentos de pesquisa: entrevistas semiestruturadas com professores e grupo focal com os estudantes participantes nos jogos escolares.

Lima (2017) relata que a identidade docente é forjada desde a sua formação na Educação Básica e que particularmente cinco professores estabelecem relação e significado as suas experiências discentes e docentes a partir dos jogos escolares, ou seja, destaca que a concepção dos docentes entrevistados sobre os jogos escolares demonstra laços com suas histórias de vida. O autor também pontua que os docentes e discentes apontam que os jogos escolares favorecem o intercâmbio cultural e a interação social. As aprendizagens com ênfase nos aspectos atitudinais, produzidas em decorrência da participação dos jogos escolares, são destacadas tanto pelos estudantes participantes, quanto pelos professores. Contudo, Lima (2017) reforça a ideia que emerge da pesquisa a partir dos relatos dos docentes da iminente necessidade de se repensar a reorganização dos jogos escolares de cada campus.

Já a Dissertação de Mestrado de Mendonça (2016), vinculada à Universidade Federal do Espírito Santo, analisa e interpreta as experiências profissionais dos docentes de Educação Física do Instituto Federal de Educação Ciência e Tecnologia do Espírito Santo (IFES), considerando desde a formação inicial e continuada até as práticas pedagógicas atuais nas aulas de Educação Física no ensino técnico integrado. A pesquisa valeu-se da etnometodologia como orientação teóricometodológica e da entrevista narrativa individual como instrumento de investigação. $\mathrm{O}$ autor entrevistou sete professores com vistas a identificar experiências profissionais construídas desde a formação inicial, passando pela formação continuada e pela docência no IFES. A formação continuada demonstrou ser marcante para os professores e ocorre a partir das necessidades surgidas na prática docente. As trajetórias pertinentes às experiências esportivas, apontadas pelos docentes, foram assinaladas como significativas nas suas carreiras. Porém, o autor destaca que o tratamento pedagógico difere entre os professores, o que demonstra uma preocupação em trabalhar o esporte numa perspectiva que venha a superar a racionalidade técnica do ensino.

Mendonça (2016) constatou a existência de uma grande dificuldade em trabalhar a Educação Física na proposta do ensino técnico integrado e concluiu que as experiências profissionais mais significativas dos docentes de Educação Física no ensino técnico integrado do IFES encontram-se no contexto do esporte. Tais fatos emergem da pesquisa ao se perceber que o tratamento pedagógico dado ao tema "esporte" apresenta diferenças da concepção teórica de 
Educação e Educação Física entre os professores. Contudo, Mendonça (2016) reconhece como positivo, mesmo com alguma tensão, o fato de os professores discutirem sobre os eventos esportivos, pois compreende que o diálogo pode permitir uma proposta diferenciada para o esporte.

\section{Etapas de Ensino}

Esta categoria compreende os estudos que se referem a diferentes etapas de ensino. A Educação de Jovens e Adultos (EJA) foi contemplada por Souza Filho e Souza (2010) e Carvalho (2017). Otte (2013) e Sousa (2016) abordaram o Ensino Médio Técnico Integrado. Já Batista, Oliveira e Melo (2012) trataram especificamente do primeiro ano do Ensino Médio Integrado.

Carvalho (2017) buscou investigar a não inclusão da Educação Física no currículo do Programa Nacional de Integração da Educação Profissional com a Educação Básica na Modalidade de Educação de Jovens e Adultos (PROEJA), implantado, em 2006, no Instituto Federal de Educação, Ciência e Tecnologia do Rio de Janeiro (IFRJ). O estudo, vinculado à Universidade Salgado de Oliveira, objetivou compreender o porquê da não inclusão da referida disciplina e o motivo da inclusão da disciplina Qualidade de Vida no currículo. O autor realizou uma pesquisa quali-quanti, que abarcou entrevistas semiestruturadas com professores e alunos do curso, além de análise documental. O resultado da análise revelou desconhecimento dos entrevistados em relação à legislação educacional, no que diz respeito à obrigatoriedade da Educação Física no currículo da Educação de Jovens e Adultos (EJA) no Ensino Médio. Carvalho (2017) também destacou a visão simplista dos entrevistados, pois associam o componente curricular Educação Física às práticas esportivas.

Para Carvalho (2017) a Educação Física no PROEJA passa a se constituir no momento da inserção da disciplina de "Qualidade de Vida I e II" em que os conteúdos teóricos e práticos passam a promover relação com a área da "Saúde: Educação Física", principalmente quando ministradas por professores específicos da EFI. Assim, emerge do trabalho de campo do autor o reconhecimento por parte dos alunos sobre a importância da Educação Física para a qualidade de vida no sentido de promoção da saúde, sendo capazes de assumirem uma postura ativa para a prática de atividade física regular. Carvalho (2017) reconheceu a potencialidade do momento para as alterações e inserção da Educação Física no currículo do PROEJA sustentado na Lei no 13.415 (BRASIL, 2017), que altera a Lei no 9.394, de 20 de dezembro de 1996 (BRASIL, 1996), assim como as discussões promovidas na Base Nacional Comum Curricular.

O PROEJA é um programa do Ministério da Educação (MEC) que objetiva a escolarização e a formação profissional de jovens e adultos, sendo destinado para pessoas que concluíram apenas o ensino fundamental e desejam adquirir o certificado do curso técnico em nível médio ${ }^{2}$. A temática do PROEJA também é abordada no artigo de Souza Filho e Souza (2010). Os autores abordam a Educação Física no PROEJA do IFRN, a partir das experiências corporais anteriores dos alunos dessa instituição. Para tanto os autores se utilizaram da concepção pedagógica do ensino

\footnotetext{
${ }^{2}$ Disponível em: <http://www.educacao.pr.gov.br/modules/conteudo/conteudo.php?conteudo=99>. Acesso em: 25 jul. 2019.
} 
aberto sustentado em Hildebrandt-Stramann para o desenvolvimento das aulas de Educação Física. Essa escolha se deu porque tal abordagem se adequava melhor à realidade dos alunos, sendo capaz de promover a participação, a orientação das atividades em grupos e a distribuição de responsabilidades favorecendo o processo de ensino e aprendizagem.

A pesquisa de Souza Filho e Souza (2010) foi fundamentada na investigação descritiva qualitativa e no questionário aberto, no qual os alunos expressaram suas vivências corporais na infância. Durante a análise dos questionários, os autores identificaram que, no Ensino Fundamental, as atividades físicas eram centradas nas práticas de senso comum do conhecimento da cultura corporal acerca do movimento humano. Os autores avaliam que o reconhecimento das práticas corporais anteriores dos participantes da pesquisa lhes permitiu identificar e ressignificar as perspectivas de ação pedagógica para o ensino da Educação Física, tais como: considerar o interesse do conhecer, do tematizar e do vivenciar a cultura de movimento. Assim, as práticas pedagógicas promovem a inclusão da cultura local, a partir das relações sociais, econômicas e políticas, contribuindo para a emancipação socioeducativa dos sujeitos do PROEJA (SOUZA FILHO; SOUZA, 2010).

Enfocando o Ensino Médio Integrado, a Dissertação de Mestrado de Otte (2013), vinculada à Universidade Federal de Pelotas, trata-se de um estudo de intervenção do tipo experimental desenvolvido no Instituto Federal de Educação, Ciência e Tecnologia Sul-rio-grandense. $O$ estudo apresenta como objetivo geral analisar a implantação do projeto "Educação Física +: Praticando Saúde na Escola" junto à disciplina de Educação Física no Ensino Médio Integrado da Rede Pública Federal. O referido projeto de intervenção baseia-se em quatro estratégias que abarcam: oficina de formação com professores, qualificação do currículo da Educação Física, intercâmbio sistemático de experiências entre os professores e cartazes educativos.

O estudo de Otte (2013) envolveu professores de Educação Física e alunos do 1o ao 3o ano do Ensino Médio Técnico Integrado dos seguintes Campi do Instituto Federal de Educação, Ciência e Tecnologia Sul-rio-grandense: Charqueadas, Sapucaia do Sul, Bagé e Venâncio Aires. O autor aponta que os alunos foram avaliados através de um questionário padronizado (composto por questões relativas a variáveis demográficas, socioeconômicas e comportamentais) antes e após a intervenção. O nível de atividade física dos alunos também foi avaliado por meio de um questionário. Já os conhecimentos dos alunos sobre atividade física e saúde foram medidos através de uma prova. Entrevistas com os professores envolvidos durante o período de intervenção foram realizadas com auxílio de questionário semiestruturado.

De acordo com Otte (2013,) a intervenção esteve fundamentada na intenção de auxiliar professores de Educação Física a problematizar a temática atividade física e saúde em suas aulas, por meio de metodologias teórico-práticas. $O$ autor destaca que não houve melhora nos níveis de atividade física dos alunos, mas considera que o conhecimento dos mesmos tenha apresentado modificações positivas após a intervenção.

Também enfocando o Ensino Médio Integrado, a Dissertação de Mestrado de Sousa (2016), vinculada à Universidade Federal do Rio Grande do Norte, apresenta-se articulada aos princípios de cunho teórico crítico, reflexivo e criativo. A autora empregou a metodologia científica da pesquisa-ação para compreender as novas problemáticas propostas pelos estudantes, tendo como 
referência os esportes de aventura nas aulas de Educação Física no Ensino Médio Integrado de um Campus do Instituto Federal do Rio Grande do Norte (IFRN). O objetivo geral do estudo foi compreender como o esporte de aventura pode se materializar no âmbito da Educação Física escolar a partir da mídia-educação como metodologia de ensino.

Sousa (2016) utilizou a metodologia da pesquisa-ação para balizar uma intervenção pedagógica realizada no Campus Parnamirim do Instituto Federal de Educação, Ciência e Tecnologia - IFRN. O estudo evidenciou três categorias de conteúdos: 1) Fatos destacados durante a aventura vivida; 2) Sentimentos de pertencimento à experiência vivida; e 3) Aprendizados autodeclarados da aventura vivida. Por meio da análise das categorias, a autora destaca que os alunos ampliaram seus conhecimentos sobre o esporte de aventura, a partir dos conteúdos midiáticos e sua sustentação teórica especializada, associada ao processo de aprendizagem que permitiu a realização de um diálogo crítico, reflexivo e criativo.

Já o artigo de Batista, Oliveira e Melo (2012) parte de reflexões teórico-metodológicas com objetivo de pensar sobre as experiências pedagógicas realizadas nas aulas de Educação Física de um Campus do IFRN, especificamente com alunos do primeiro ano do Ensino Médio Integrado, pautadas por duas questões: O que entendemos por aprendizagem? Que caminhos teóricometodológicos podem ser traçados para que as aulas de Educação Física possibilitem aprendizagens mais significativas? Para tanto, os autores promoveram a discussão sobre a cultura de movimento como conhecimento pedagógico da EFI e suas diversas manifestações. As aulas foram divididas em três momentos distintos. No primeiro foram discutidos conceitos e características do jogo como manifestação da cultura de movimento, no segundo momento vivenciaram jogos que produziram as discussões originadas no encontro anterior e no último momento a entrega, apresentação e discussão realizada durante os seminários, no qual emergiram potentes questões, tais como: Jogar é coisa de criança? Que tipos de jogos e brincadeiras fizeram parte da infância dos alunos, dos pais e avós? O que provocou tais mudanças de hábito de jogar? Quais as diferenças entre jogo e esporte? Por fim, nessa aula os alunos tiveram a oportunidade de se posicionar criticamente com relação aos conteúdos desenvolvidos em aula.

Para os autores o envolvimento dos alunos com o processo foi capaz de promover a transformação da cultura corporal, pois permitiu outra visão e sentido para a cultura corporal de movimento, assim como para os docentes que compreenderam que a contextualização do conteúdo feito pelo aluno sinaliza para a construção de significativas aprendizagens. Deste modo, os autores apontam que um dos caminhos que poderá levar os discentes ao processo de aprendizagem significativo perpassa uma proposta didática e metodológica de ensino que contemple a reflexão, o contexto, a criatividade, a autonomia, os conhecimentos anteriores e o planejamento. Para Batista, Oliveira e Melo (2012), tais apontamentos são capazes de contribuir ativamente para a superação de práticas mecanicistas.

Do conjunto de investigações analisadas, é importante destacar que o tema esporte perpassa todas as categorias de análise, sendo que a metade dos estudos encontrados apresentam a temática esporte de modo central. Este fato demonstra a força que o esporte ainda exerce relacionado ao currículo da Educação Física escolar, muitas vezes em detrimento de outros conteúdos. 
A análise dos artigos científicos, encontrados no levantamento realizado no Portal de Periódicos da CAPES, permitiu visualizar a Revista $\mathrm{Holos}^{3}$ como principal meio de socialização do conhecimento produzido sobre os Institutos Federais. Chama a atenção o fato de que todos os artigos selecionados para análise, ou seja, aqueles que preencheram os requisitos para seleção, foram publicados nessa revista científica e têm o Instituto Federal do Rio Grande do Norte (IFRN) como lócus de pesquisa. Os Institutos Federais possuem diversas revistas científicas que acolhem estudos nas áreas de Ensino e Saúde, bem como interdisciplinares, mas o levantamento empreendido não apontou artigos que enfatizassem a temática currículo aliada à área de conhecimento da Educação Física.

\section{CONSIDERAÇÕES FINAIS}

Este estudo foi sustentado em uma revisão de literatura de cunho qualitativo e objetivou compreender como a temática "Educação Física nos currículos dos Institutos Federais de Educação, Ciência e Tecnologia" vem sendo tratada na produção acadêmica científica. Investigamos a produção acadêmica e científica do Catálogo de Dissertações e Teses da CAPES e do Portal de Periódicos da CAPES. Para tal, realizamos um levantamento, usando, em conjunto, os seguintes termos de busca: "Instituto Federal de Educação, Ciência e Tecnologia", "Educação Física" e "Currículo". O referido levantamento nos permitiu analisar oito Dissertações de Mestrado, uma Tese de Doutorado e três artigos científicos.

Os achados foram organizados em três categorias de análise: Esportivização, Formação Docente, Etapas de Ensino. Por meio da análise realizada, foi possível constatar que o tema currículo é abordado nos estudos encontrados, mas somente quatro enfatizam esta temática de forma central. Entendemos que o levantamento realizado no Portal de Periódicos CAPES e no Catálogo de Teses e Dissertações da CAPES evidencia uma baixa produção acadêmica da área de conhecimento da Educação Física sobre a temática. Nessa perspectiva, compreendemos que possa existir uma relação direta com o fato de os IFs terem sido criados recentemente, há pouco mais de dez anos, sendo que, nesse período, essas instituições passaram por três fases de expansão e que esse processo pode não ter permitido a implementação da concepção de educação profissional e tecnológica sustentada nos princípios de ensino, pesquisa e extensão de modo efetivo e contínuo.

Evidenciamos que os estudos analisados estabelecem uma relação de produção do conhecimento, sustentado na sua própria prática educativa, ou seja, os professores de Educação Física pesquisaram a sua específica aplicação nos Institutos Federais. Contudo, propusemos um olhar crítico e reflexivo sobre os elementos que emergem da análise, pois identificamos que a metade dos estudos apresentam o tema esporte de modo central nas pesquisas, sendo que os demais trabalhos abordaram assuntos como: EJA e EFI; Experiências profissionais dos docentes de EFI; Educação Física e a saúde na escola; EFI e a cultura no Ensino Médio Integrado do IF; Experiências pedagógicas nas aulas de EFI; e Educação Física no currículo do PROEJA. Desse modo, compreendemos que a produção do conhecimento sobre a Educação Física se concentra na temática hegemônica do esporte. Destacamos que não se trata de ser contra o esporte, mas de

\footnotetext{
${ }^{3}$ Holos é uma publicação do IFRN, disponível on-line, que visa a divulgar artigos que contribuam para pesquisas de temas multidisciplinares
} 
reconhecer qual representatividade desse conteúdo no componente curricular Educação Física no currículo dos Institutos Federais e no desenvolvimento da tríade ensino, pesquisa e extensão. Em vista disso, passamos a compreender de forma significativa a necessidade de aprofundar, ampliar e socializar os conhecimentos acadêmicos e científicos desenvolvidos sobre a Educação Física como componente curricular dos Institutos Federais de Educação, Ciência e Tecnologia.

A revisão de literatura realizada no Portal de Periódicos da CAPES, especificamente, permitiu visualizar a existência de uma produção acadêmica qualificada, oriunda do Instituto Federal do Rio Grande do Norte e a utilização da Revista Holos como principal meio de socialização do conhecimento produzido nessa instituição. Compreendemos que há um esforço significativo da Educação Física, área de conhecimento, de se localizar como componente curricular, no sentido de consolidar a proposta pedagógica dos Cursos Técnicos de Ensino Médio Integrado dos IFs, além de ressignificar o modo como os conteúdos são desenvolvidos e estabelecer sentido ao que se aprende e como se aprende.

Por fim, destacamos que a análise realizada diz respeito unicamente aos estudos encontrados e selecionados por meio da revisão de literatura empreendida, portanto não envolve toda a produção existente sobre os termos usados no levantamento e não pode ser tomada como generalizante.

\section{REFERÊNCIAS}

Apple, M. W. (2001). Política Cultural e Educação. São Paulo: Editora Cortez.

Bardin, Laurence. (2011). Análise de Conteúdo. São Paulo: Edições 70.

Batista, A. P.; Oliveira, I. P. B.; Melo, J. P. (2012). Corpo, Aprendizagem e Cultura de Movimento: uma experiência pedagógica com o ensino do conteúdo jogo nas aulas de Educação Física do IFRN Revista Holos. Natal, ano 28, v. 6, p. 237-248.

Batista, A. P. et al. (2014). Possibilidades e Desafios da Educação Física como Componente Curricular no Processo de Expansão Regional do Instituto Federal de Educação, Ciências e Tecnologia do Rio Grande do Norte - IFRN. Revista Holos. Natal, ano 30, v. 4, p. 492-501.

Brasil. (1996). Presidência da República. Lei № 9.394: de 20 de dezembro de 1996. Estabelece as diretrizes e bases da educação nacional. Recuperado em 10 de setembro de 2018, de http://www.planalto.gov.br/Ccivil_03/leis/L9394.htm.

Brasil. (2008). Presidência da República. Lei № 11.892: de 29 de dezembro de 2008. Institui a Rede Federal de Educação Profissional, Científica e Tecnológica, cria os Institutos Federais de Educação, Ciência e Tecnologia, e dá outras providências. Recuperado em 01 julho, 2017, de https://www.planalto.gov.br/ccivil_03/_ato2007-2010/2008/lei/l11892.htm.

Brasil. (2017). Presidência da República. Lei № 13.415: de 16 de fevereiro de 2017. Altera as Leis no 9.394, que estabelece as Diretrizes e Bases da Educação Nacional e 11.494 que regulamenta o Fundo de Manutenção e Desenvolvimento da Educação Básica e de Valorização dos Profissionais da Educação. Recuperado em 01 julho, 2017, de http://www.planalto.gov.br/ccivil_03/_Ato2015-2018/2017/Lei/L13415.htm. 
Cancella, A. S. (2018). A oferta do esporte para os alunos com deficiência no Instituto Federal do Paraná - IFPR, Campus Paranaguá: um movimento de reprodução ou resistência? 2018. 145 f. Dissertação (Mestrado) - Programa de Pós-Graduação em Educação Física. Universidade Federal do Paraná, UFPR, Curitiba, Brasil.

Carvalho, R. L. de. (2017). A ausência da Educação Física no currículo da Educação de Jovens e Adultos: um estudo no Campus Rio de Janeiro do Instituto Federal de Educação, Ciência e Tecnologia do Rio de Janeiro (IFRJ). 2017. 156 f. Dissertação (Mestrado) - Programa de PósGraduação Stricto Sensu em Ciências da Atividade Física. Universidade Salgado de Oliveira, Niterói, Brasil.

Creswell, J. W. (2014). Investigação qualitativa e projeto de pesquisa: escolhendo entre cinco abordagens. Tradução: Sandra Mallmann da Rosa. Porto Alegre: Penso.

Darido, S. C.; Rangel, I. C. A. (2011). Educação Física na escola: implicações para a prática pedagógica. Rio de Janeiro: Editora Guanabara Koogan.

González, Fernando Jaime. (2008). Esportivização. In: González, Fernando Jaime; Fensterseifer, Paulo Evaldo. Dicionário Crítico da Educação Física. Ijuí: Editora Unijuí, 2008.

Hildebrandt, R. (1986). Concepções abertas no Ensino da Educação Física. Rio de Janeiro. Ao Livro técnico.

Ilha, Franciele Roos da Silva; Hypolito, Álvaro Moreira. (2016). Esportivização da Educação Física escolar: um dispositivo e seus regimes de enunciação. Movimento, Porto Alegre, v. 22, n. 1, 173-186, jan./mar.

Kunz, E. (1991). Educação Física: Ensino e mudanças. Ijuí, Editora Unijuí.

Lima, J. de A. (2017). Práticas curriculares na Educação Física: análise dos jogos escolares do Instituto Federal Sertão Pernambucano. 2017. 174 f. Dissertação (Mestrado) - Programa de Pós-Graduação em Educação Física. Universidade Federal do Vale do São Francisco, UNIVASF, Petrolina, Brasil.

Medeiros, V. M. L. D. (2015). Sentidos do Componente Curricular Educação Física no Ensino Técnico Integrado ao Médio em João Pessoa/PB: Discursos em Diálogos. 2015. Tese (Doutorado) Centro de Educação. Universidade Federal da Paraíba, UFPB, João Pessoa, Brasil.

Mendonça, G. C. de. (2016). Narrativas de Experiências Profissionais de Docentes de Educação Física no Ensino Técnico Integrado do Instituto Federal de Educação, Ciência e Tecnologia. 2016. 146 f. Dissertação (Mestrado) - Centro de Educação Física e Desportos. Universidade Federal do Espírito Santo, Programa de Pós-Graduação em Educação Física, UFES, Vitória, Brasil.

Molina Neto, Vicente; Bossle, Fabiano; Wittizorecki, Elisandro Schultz. (2010). Formação de professores de Educação Física. In: Terra, Dinah Vasconcellos; Souza Junior, Marcílio. Formação em Educação Física \& Ciências do Esporte: políticas e cotidiano. São Paulo: Aderaldo\& Rothschild: Goiânia, GO: CBCE. 
Neira, M. G.; Nunes, M. L. F. (2009). Educação Física, Currículo e Cultura. São Paulo: Editora Phorte.

Noronha, D. P.; Ferreira, S. M. S. P. (2000). Revisões de literatura. In Campello, B. S.; Condón, B. V.; Kremer, J. M. (Orgs.). Fontes de informação para pesquisadores e profissionais. Belo Horizonte: UFMG.

Otte, J. (2013). Intervenção em Educação Física escolar: promovendo atividade física e saúde no ensino médio. 2013. 166 f. Dissertação (Mestrado) - Escola Superior de Educação Física. Universidade Federal de Pelotas, UFPel, Pelotas, Brasil.

Pacheco, E. (Org.). (2011). Institutos Federais: uma revolução na educação profissional e tecnológica. Brasília: Moderna.

Palma, L. C.; Alves, N. B.; Silva, T. N. da. (2013). Educação para a Sustentabilidade: a construção de caminhos no Instituto Federal de Educação, Ciência e Tecnologia do Rio Grande do Sul (IFRS). Revista de Administração Mackenzie. 14(3), 83-118.

Pirolo, A. L.; Caparróz, D. A.; Terra, D. V.; Caparróz, F. E.; Palafox, G. H. M. (2014). Currículo. In Gonzales, F. J.; Fensterseifer, P. E. (Orgs.). Dicionário Crítico de Educação Física. Ijuí: Editora UNIJUÍ, p. 182-185.

Ramos, E. P. (2015). Participação de Alunos do Ensino Médio Integrado ao Ensino Profissionalizante em Atividades Extracurriculares de Esporte e Lazer em um Campus de um Instituto Federal em Minas Gerais-MG. 2015. 79f. Dissertação (Mestrado) - Faculdade de Ciências da Saúde. Universidade Metodista de Piracicaba, Programa de Pós-Graduação em Ciências do Movimento Humano, UNIMEP, Piracicaba, Brasil.

Sacristán, J. G. (2000). O currículo: uma reflexão sobre a prática. Porto Alegre: Artmed.

Sacristán, J. G. (2013). (Org.). Saberes e incertezas sobre o currículo. Tradução: Alexandre Salvaterra. Porto Alegre: Penso.

Santos, R. F. dos. (2016). Esporte, Lazer e Cultura: os significados dos projetos de esporte e lazer do Instituto Federal do Norte de Minas Gerais - Campus Januária para alunos participantes e não participantes. 2016. 186f. Dissertação (Mestrado) - Faculdade de Ciências da Saúde. Universidade Metodista de Piracicaba, Programa de Pós-Graduação em Ciências do Movimento Humano, UNIMEP, Piracicaba, Brasil.

Silva, E. M. (2014). A Educação Física no Currículo de Escolas Profissionalizantes da Rede Federal: uma disciplina em processo de "mutação". 2014. 148 f. Tese (Doutorado) - Curso da Escola de Educação Física. Universidade Federal do Rio Grande do Sul, Departamento de Programa de Pós-Graduação em Ciências do Movimento Humano, UFRGS, Porto Alegre, Brasil.

Soares, C. L.; Taffarel, C. N. Z.; Varjal, E.; Castellani Filho, L.; Escobar, M. O.; Bracht, V. (2012). Metodologia do Ensino de Educação Física. São Paulo: Cortez.

Sousa, D. Q. de O. (2016). Esporte de Aventura na Escola: possibilidades de diálogo com a mídiaeducação. 2016. 171 f. Dissertação (Mestrado) - Centro de Ciências da Saúde. Universidade 
Federal do Rio Grande do Norte, Departamento de Educação Física, Programa de Pósgraduação em Educação Física, UFRN, Natal, Brasil.

Souza Filho, M. de; Souza, H. A. G. de. (2010). A Educação Física no PROEJA do IFRN - Campus Natal Zona Norte: uma experiência pedagógica. Revista Holos. 1, 141-152. 